\title{
Integrated results from the COPERNICUS and GALILEO studies
}

\section{Amelie Pielen, ${ }^{1,2} \mathrm{~W}$ Lloyd Clark, ${ }^{3}$ David S Boyer, ${ }^{4}$ Yuichiro Ogura, ${ }^{5}$ Frank G Holz, ${ }^{6}$ Jean-Francois Korobelnik, ${ }^{7,8}$ Brigitte Stemper, ${ }^{9,10}$ Friedrich Asmus, ${ }^{9}$ Kay D Rittenhouse," ' Christiane Ahlers, ${ }^{9}$ Robert Vitti, ${ }^{12}$ Namrata Saroj, ${ }^{12}$ Oliver Zeitz,, ${ }^{9,13}$ Julia A Haller ${ }^{15}$ \\ On behalf of the COPERNICUS and GALILEO study group} Eye Hospital, Freiburg, ${ }^{2} \mathrm{Hannover}$ Medical School, University Eye Hospital, Hannover, Germany; ${ }^{3}$ Palmetto Retina Center, Columbia, SC, USA; ${ }^{4}$ Retina-Vitreous Associates Medical Group, Beverly Hills, CA, USA; ${ }^{5}$ Department of Ophthalmology and Visual Science, Nagoya City

University Graduate School of Medical Sciences, Nagoya, Japan; ${ }^{6}$ Department of Ophthalmology, University of Bonn, Bonn, Germany; ' 'Service d'ophtalmologie, $\mathrm{CHU}$ de Bordeaux, ${ }^{8}$ Service d'ophtalmologie, University of Bordeaux, Inserm, Bordeaux Population Health Research Center Team LEHA, UMR 1219, Bordeaux, France; 'Bayer AG, Berlin, ${ }^{10}$ Department of Neurology, University of ErlangenNuremberg, Erlangen, Germany; "Bayer US LLC, Whippany, NJ, ${ }^{12}$ Regeneron Pharmaceuticals, Tarrytown, NY, USA; ${ }^{13} \mathrm{AKH}$ Eye Clinic, Braunschweig,

${ }^{14}$ Universitätsklinikum Hamburg-Eppendorf, Klinik und Poliklinik für Augenheilkunde, Hamburg, Germany; ${ }^{15}$ Wills Eye

Hospital,Thomas Jefferson University, Philadelphia, PA, USA Hanover Medical School, University Eye Hospital, Carl-Neuberg-Strasse I, 30625 Hannover, Germany

Tel +49 5II 5233060

Fax +4951I 5323050

Email pielen.amelie@mh-hannover.de
'Eye Center, University Hospital Freiburg,

Correspondence: Amelie Pielen

This article was published in the following Dove Press journal:

Clinical Ophthalmology

23 August 2017

Number of times this article has been viewed

Objectives: To report on the efficacy and safety of intravitreal aflibercept in patients with macular edema secondary to central retinal vein occlusion (CRVO) in an integrated analysis of COPERNICUS and GALILEO.

Patients and methods: Patients were randomized to receive intravitreal aflibercept $2 \mathrm{mg}$ every 4 weeks or sham injections until week 24. From week 24 to week 52, all intravitreal aflibercept-treated patients in both studies and sham-treated patients in COPERNICUS were eligible to receive intravitreal aflibercept based on prespecified criteria. In GALILEO, shamtreated patients continued to receive sham treatment through week 52.

Results: At week 24, mean gain in best-corrected visual acuity and mean reduction in central retinal thickness were greater for intravitreal aflibercept-treated patients compared with sham, consistent with individual trial results. At week 52, after 6 months of intravitreal aflibercept as-needed treatment in COPERNICUS, patients originally randomized to sham group experienced visual and anatomic improvements but did not improve to the extent of those initially treated with intravitreal aflibercept, while the sham group in GALILEO did not improve over week 24 mean best-corrected visual acuity scores. Ocular serious adverse events occurred in $<10 \%$ of patients.

Conclusion: This analysis of integrated data from COPERNICUS and GALILEO confirmed that intravitreal aflibercept is an effective treatment for macular edema following CRVO.

Keywords: macular edema, central retinal vein occlusion, anti-vascular endothelial growth factor, aflibercept, COPERNICUS, GALILEO

\section{Introduction}

Retinal vein occlusion is a common cause of vision loss worldwide ${ }^{1}$ and is the second most common retinal vascular disease after diabetic retinopathy. ${ }^{2}$ The Beaver Dam Eye Study found that the prevalence of central retinal vein occlusion (CRVO) was $0.1 \%$ and the 5 -year incidence was $0.2 \%$, while the 15 -year cumulative incidence of CRVO is $0.5 \% .^{3,4}$ Most recently, a pooled analysis of data from $>68,000$ individuals found that 2.5 million adults are affected by CRVO. ${ }^{5}$ Pharmacologic therapies such as intravitreal anti-vascular endothelial growth factor (anti-VEGF) agents and intravitreal steroids are shown to be of benefit for eyes with macular edema secondary to CRVO. ${ }^{6}$ Due to the side effects associated with steroid use, including increased intraocular pressure and cataract, anti-VEGF agents have emerged as first-line therapy for most eyes with retinal vein occlusions.

Two anti-VEGF agents are currently approved by the US Food and Drug Administration for the treatment of macular edema due to CRVO: ranibizumab and aflibercept. Bevacizumab is additionally used for this indication on an off-label basis. Aflibercept is a fusion protein of key domains from human VEGF receptors 1 and 2 
with the constant region ( $\mathrm{Fc}$ ) of human immunoglobulin $\mathrm{G}$ that binds to multiple VEGF-A isoforms with a high affinity. ${ }^{7,8}$ Intravitreal aflibercept was approved for the treatment of macular edema due to CRVO after its efficacy and safety were demonstrated in the two Phase III studies, COPERNICUS and GALILEO. ${ }^{9-14}$

Results of the integrated analyses from COPERNICUS and GALILEO have not been published. Integrating data from both studies increases the number of patients included in the treated population, thus increasing the generalizability of the results to the global population and minimizing the risk of any outlier effect that might be seen in the individual studies. Integrating the data also strengthens the ability to detect any safety signals and characterizes the safety profile of intravitreal aflibercept. Here, we report on the efficacy and safety of intravitreal aflibercept at 52 weeks in patients with macular edema secondary to CRVO in an integrated analysis of data from the COPERNICUS and GALILEO studies. Sham-treated patients in the COPERNICUS study were eligible to receive intravitreal aflibercept starting at week 24, whereas patients in GALILEO continued sham treatment through week 52. As treatment schedules and the duration of the two studies differed beyond week 52, integrated data are shown here only through the week 52 visits.

\section{Patients and methods \\ Design}

COPERNICUS and GALILEO were parallel randomized, double-masked Phase III studies comparing intravitreal aflibercept with sham for the treatment of macular edema secondary to CRVO. The details of these studies have been published previously; ${ }^{9-14}$ key aspects of study design and conduct are described here. COPERNICUS was conducted at 61 sites in the United States, Canada, Colombia, India, and Israel and GALILEO at 63 sites in Asia and Europe. The duration of COPERNICUS was 100 weeks and GALILEO was 76 weeks. The studies were conducted in compliance with ethical guidelines from the Declaration of Helsinki and International Conference on Harmonisation and are registered on ClinicalTrials.gov as NCT00943072 and NCT01012973, respectively. Institutional Review Board/Ethics Committee approval was obtained at each site before the start of the studies (Supplementary materials). All patients signed a written consent form before initiation of study-specific procedures.

\section{Patients}

Patients with center-involved macular edema due to CRVO for $\leq 9$ months were included if they were treatment naïve, aged $\geq 18$ years, and had a mean central retinal thickness $(\mathrm{CRT}) \geq 250 \mu \mathrm{m}$ on optical coherence tomography and a best-corrected visual acuity (BCVA) of 73-24 Early Treatment Diabetic Retinopathy Study (ETDRS) letters in the study eye. Only one eye per patient was included.

Exclusion criteria comprised the following: pregnancy or lactation; uncontrolled glaucoma (intraocular pressure $\geq 25 \mathrm{mmHg}$ ); cataract, vitreoretinal, or filtration surgery; bilateral manifestation of retinal vein occlusion; iris neovascularization; any ocular disorder in the study eye that, in the opinion of the investigator, may have confounded the interpretation of the study results; or previous treatment with any anti-VEGF agents, systemic anti-angiogenic medications, or intraocular corticosteroids. Retinal ischemia and afferent pupillary defect were not causes for exclusion.

\section{Randomization and treatments}

Patients were randomized in a 3:2 ratio to receive intravitreal aflibercept $2 \mathrm{mg}$ every 4 weeks or sham injections until week 24. From week 24 to week 52, all intravitreal aflibercept-treated patients in both studies and sham-treated patients in COPERNICUS were eligible to receive intravitreal aflibercept based on prespecified retreatment criteria. Sham-treated patients in GALILEO were eligible to receive intravitreal aflibercept after week 52. Treatment groups are shown in Table 1.

The prespecified retreatment criteria included increase of $>50 \mu \mathrm{m}$ from lowest previous measurement, new/ persistent cystic retinal changes or subretinal fluid or persistent diffuse edema of $\geq 250 \mu \mathrm{m}$ in the central subfield,

Table I Treatment groups

\begin{tabular}{|c|c|c|c|c|}
\hline \multirow{2}{*}{$\begin{array}{l}\text { Treatment } \\
\text { groups }\end{array}$} & \multicolumn{2}{|l|}{ COPERNICUS } & \multicolumn{2}{|l|}{ GALILEO } \\
\hline & Baseline to week 20 & Week 24 to week 52 & Baseline to week 20 & Week 24 to week 52 \\
\hline \multirow[t]{2}{*}{ Sham } & Sham injection every & Intravitreal aflibercept & Sham injection every & Sham injection every \\
\hline & 4 weeks & $2.0 \mathrm{mg}$ PRN & 4 weeks & 4 weeks \\
\hline Intravitreal & Intravitreal aflibercept & Intravitreal aflibercept & Intravitreal aflibercept & Intravitreal aflibercept \\
\hline aflibercept & $2.0 \mathrm{mg}$ every 4 weeks & $2.0 \mathrm{mg}$ PRN & $2.0 \mathrm{mg}$ every 4 weeks & $2.0 \mathrm{mg}$ PRN \\
\hline
\end{tabular}

Abbreviation: PRN, pro re nata (as needed). 
loss of $\geq 5$ ETDRS letters from best previous measurement with any increase in CRT, and increase of $\geq 5$ ETDRS letters between current and most recent visit in the absence of retinal edema in the central subfield. Patients who did not meet any of the retreatment criteria were given sham injections to maintain masking. In case of neovascular complications (eg, neovascularization of the anterior segment, at the optic disk, or elsewhere in the fundus), patients were eligible for treatment with panretinal photocoagulation.

\section{Outcomes}

The primary end point was the proportion of eyes that gained $\geq 15$ letters in BCVA at week 24 . Herein, results are presented for the integrated COPERNICUS and GALILEO studies. Results from baseline to week 24 are presented for two groups of patients: the intravitreal aflibercept group $(n=217)$ and the sham group $(n=141)$. Results from week 24 to week 52 are presented for three groups of patients: the intravitreal aflibercept group $(n=217)$, the sham $\rightarrow$ intravitreal aflibercept group (ie, patients in COPERNICUS originally randomized to sham injections who crossed over to active treatment after week $24 ; n=73$ ), and the sham group (ie, patients in GALILEO originally randomized to sham injections who had not crossed over to active treatment by week $52 ; \mathrm{n}=68$ ).

\section{Statistics}

All safety and efficacy variables were analyzed descriptively with appropriate statistical methods: categorical variables by frequency tables (absolute and relative frequencies) and continuous variables by sample statistics (ie, mean, standard deviation). Patients included in the evaluations are those from the full analysis set, which includes all randomized subjects who received any study medication and had at least one baseline and one post-baseline assessment. The full analysis set was analyzed as randomized. For missing efficacy data after start of treatment, the last observation carried forward (LOCF) approach was applied. Safety analysis included all patients who received any study treatment.

\section{Results}

When data from the two studies were integrated, baseline demographic and disease characteristics were similar across the two treatment groups (Table 2). Mean age at baseline was 62.9 years in the intravitreal aflibercept group and 65.7 years in the sham group. Mean baseline BCVA was 52.0 letters in the intravitreal aflibercept group and 49.9 letters in the sham group. The majority of patients in both treatment groups had perfused retinas (classified as $<10$ disk areas of retinal capillary non-perfusion on fluorescein angiography) at baseline $(76.5 \%$ of patients in the intravitreal aflibercept group and $73.8 \%$ in the sham group). There were fewer patients with perfused retinas at baseline in COPERNICUS than GALILEO (67.9\% versus 83.6\%).

From baseline to week 24 , the mean (standard deviation) number of injections received in the intravitreal aflibercept group was 5.8 (0.8). Among patients who completed at least through week 24, the mean (standard deviation) number of active injections received from week 24 to week 52 was 2.6 (1.7) in the intravitreal aflibercept group, 3.9 (2.0) in

Table 2 Baseline demographic and disease characteristics (full analysis set)

\begin{tabular}{|c|c|c|c|c|}
\hline & \multirow{2}{*}{$\begin{array}{l}\text { COPERNICUS } \\
(\mathrm{n}=187)\end{array}$} & \multirow{2}{*}{$\begin{array}{l}\text { GALILEO } \\
(n=|7|)\end{array}$} & \multicolumn{2}{|l|}{ Integrated } \\
\hline & & & $\begin{array}{l}\text { Intravitreal aflibercept } \\
\text { group }(n=2 \mid 7)\end{array}$ & $\begin{array}{l}\text { Sham group } \\
(n=\mid 4 I)\end{array}$ \\
\hline Mean (SD) age, years & $66.3(13.9)$ & $61.5(12.9)$ & $62.9(13.3)$ & $65.7(13.9)$ \\
\hline Sex, female, $n(\%)$ & $80(43.0)$ & $76(44.4)$ & $127(58.5)$ & $66(46.8)$ \\
\hline Mean (SD) BCVA, ETDRS letters & $50(14.1)$ & $52.2(15.7)$ & $52.0(14.9)$ & $49.9(14.9)$ \\
\hline Mean (SD) CRT, $\mu \mathrm{m}$ & $665.8(239.8)$ & $665.5(231.0)$ & $672.0(235.7)$ & $655.7(235.1)$ \\
\hline Mean (SD) time since CRVO diagnosis, months & $2.4(2.8)$ & $\mathrm{n} / \mathrm{a}^{\mathrm{a}}$ & $2.7(3.0)$ & $2.4(2.5)$ \\
\hline \multicolumn{5}{|l|}{ Perfusion status, $n(\%)$} \\
\hline Perfused & 127 (67.9) & $143(83.6)$ & $166(76.5)$ & $104(73.8)$ \\
\hline Non-perfused & $29(15.5)$ & $14(8.2)$ & $24(I I . I)$ & $19(13.5)$ \\
\hline Indeterminate & $31(16.6)$ & $14(8.2)$ & $27(12.4)$ & $18(12.8)$ \\
\hline \multicolumn{5}{|l|}{ Retinal fluid, n (\%) } \\
\hline Absent & $3(1.6)$ & $2(1.2)$ & $4(1.8)$ & I (0.7) \\
\hline Present & $182(97.9)$ & $168(98.2)$ & $211(97.2)$ & $139(99.3)$ \\
\hline Undetermined & I (0.5) & I $(0.6)$ & $2(1.0)$ & 0 \\
\hline
\end{tabular}

Note: aFor GALILEO, time since diagnosis reported in days: mean $(\mathrm{SD})=81.8$ (85.4).

Abbreviations: BCVA, best-corrected visual acuity; CRT, central retinal thickness; CRVO, central retinal vein occlusion; ETDRS, Early Treatment Diabetic Retinopathy Study; n/a, not available; SD, standard deviation. 
A

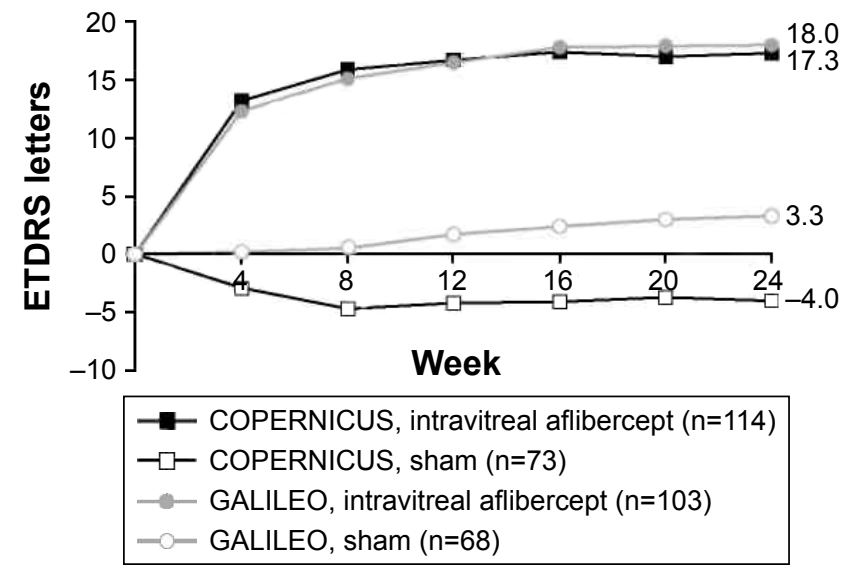

B

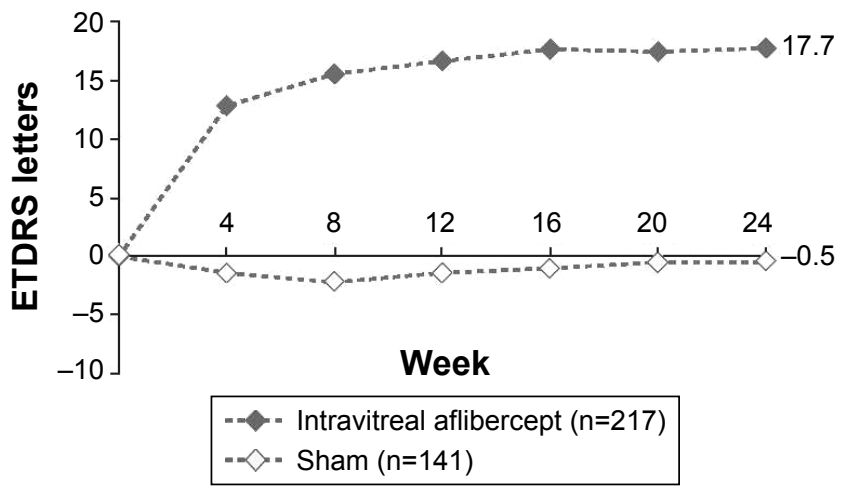

Figure I Mean change in BCVA for (A) COPERNICUS and GALILEO and (B) integrated data set from baseline to week 24 (LOCF). Abbreviations: BCVA, best-corrected visual acuity; ETDRS, Early Treatment Diabetic Retinopathy Study; LOCF, last observation carried forward.

the sham $\rightarrow$ intravitreal aflibercept group, and $0(0)$ in the sham group.

At week 24, the proportion of patients who gained $\geq 15$ letters from baseline was $60.4 \%$ in the intravitreal aflibercept group and $17.0 \%$ in the sham group. At week 52 , the proportion of patients who gained $\geq 15$ letters from baseline was $58.5 \%$ in the intravitreal aflibercept group, $30.1 \%$ in the sham $\rightarrow$ intravitreal aflibercept group (COPERNICUS), and 32.4\% in the sham group (GALILEO). Between week 24 and week 52, the proportion of patients who gained $\geq 15$ letters from baseline increased by 17.8 percentage points in the sham $\rightarrow$ intravitreal aflibercept group and by 10.3 percentage points in the sham group.

At week 24, the mean change in BCVA from baseline was +17.7 letters in the intravitreal aflibercept group and -0.5 letters in the sham group (Figure 1). At week 52, the mean change in BCVA from baseline was +16.5 letters in the intravitreal aflibercept group, +3.8 letters in the sham $\rightarrow$ intravitreal aflibercept group, and +3.8 letters in the sham group (Figure 2). Between week 24 and week 52, the mean change from baseline in BCVA increased by 7.8 letters in the sham $\rightarrow$ intravitreal aflibercept group, and by 0.5 letters in the sham group.

At week 24, the mean change in CRT from baseline was $-453.1 \mu \mathrm{m}$ in the intravitreal aflibercept group and $-157.2 \mu \mathrm{m}$ in the sham group (Figure 3). At week 52, the mean change in CRT from baseline was $-418.0 \mu \mathrm{m}$ in the intravitreal aflibercept group, $-381.8 \mu \mathrm{m}$ in the sham $\rightarrow$ intravitreal aflibercept group, and $-219.3 \mu \mathrm{m}$ in the sham group (Figure 4).

At week 52, ocular serious adverse events occurred in $16(7.3 \%), 12(16.2 \%)$, and six $(8.8 \%)$ patients in the intravitreal aflibercept group, the sham $\rightarrow$ intravitreal aflibercept group, and the sham group, respectively (Table 3). Two Antiplatelet Trialists Collaboration-defined arterial thromboembolic events (APTC-ATEs) occurred overall. One patient in the intravitreal aflibercept group experienced a non-fatal myocardial infarction and one patient in the sham $\rightarrow$ intravitreal aflibercept group experienced vascular death. There were no APTC-ATEs in the sham group (Table 4).

\section{Discussion}

The aim of this article is to report the efficacy and safety of intravitreal aflibercept in patients with macular edema due to CRVO in an integrated analysis of data from the COPERNICUS and GALILEO studies. The integrated data

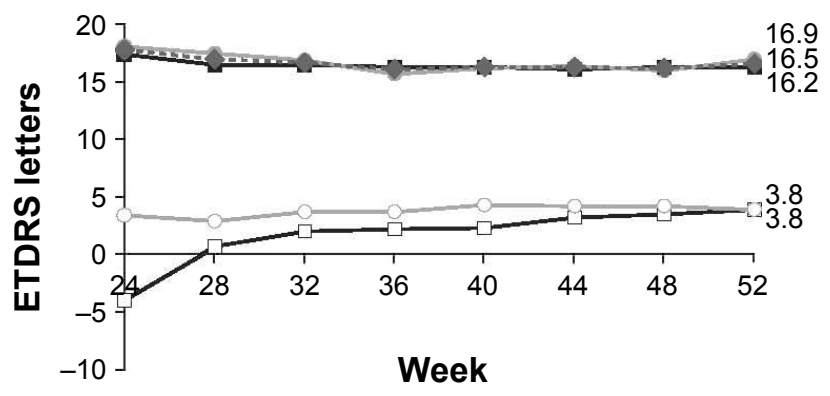

- COPERNICUS, intravitreal aflibercept $(n=114)$

$\rightarrow-$ COPERNICUS, sham $\rightarrow$ intravitreal aflibercept $(n=73)$

- - GALILEO, intravitreal aflibercept $(n=103)$

$-0-$ GALILEO, sham $(n=68)$

..... Integrated, intravitreal aflibercept $(\mathrm{n}=217)$

Figure 2 Mean change in BCVA from baseline to week 24-week 52 (LOCF). Abbreviations: BCVA, best-corrected visual acuity; ETDRS, Early Treatment Diabetic Retinopathy Study; LOCF, last observation carried forward. 
A

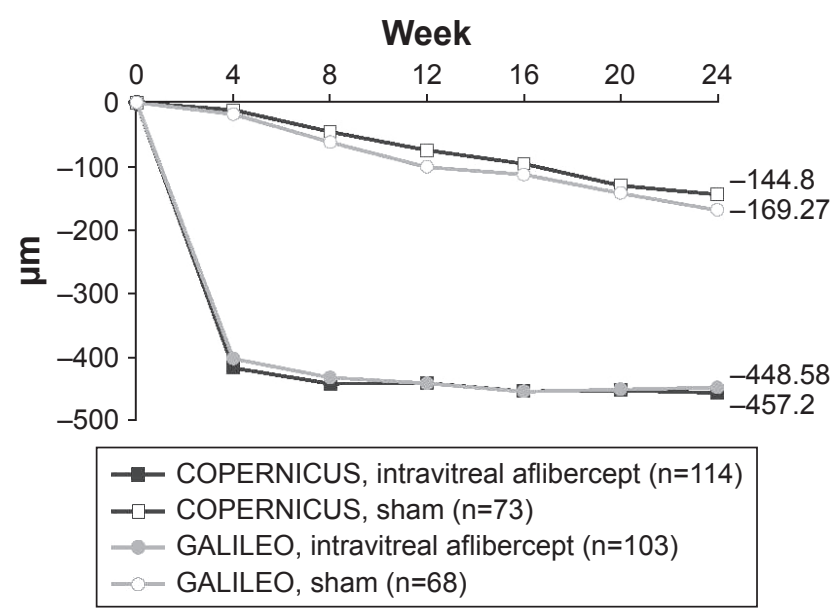

B

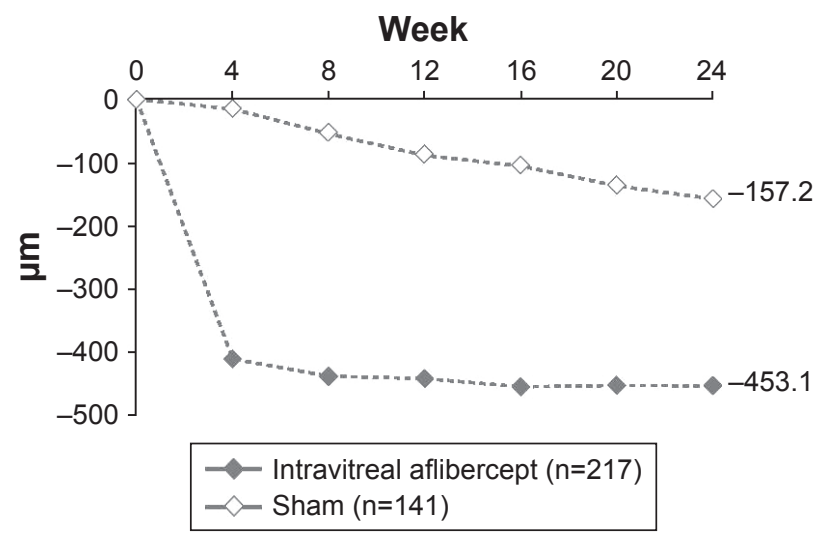

Figure 3 Mean change in CRT for (A) COPERNICUS and GALILEO and (B) integrated data set from baseline to week 24 (LOCF). Abbreviations: CRT, central retinal thickness; LOCF, last observation carried forward.

of the COPERNICUS and GALILEO studies confirm the findings of the individual studies.

Both the COPERNICUS and GALILEO studies documented the beneficial treatment effect of intravitreal aflibercept compared with sham injections; however, there were differences between the studies that should be considered. The natural history (sham-treated) groups demonstrate that the patients enrolled in the two studies were slightly different in some aspects, likely due in part to the different countries and geographic regions where they were conducted. Specifically, visual gains among patients originally randomized to sham treatment were generally lower in COPERNICUS than those in GALILEO, both before and after initiation of treatment with intravitreal aflibercept at week 24 . This finding

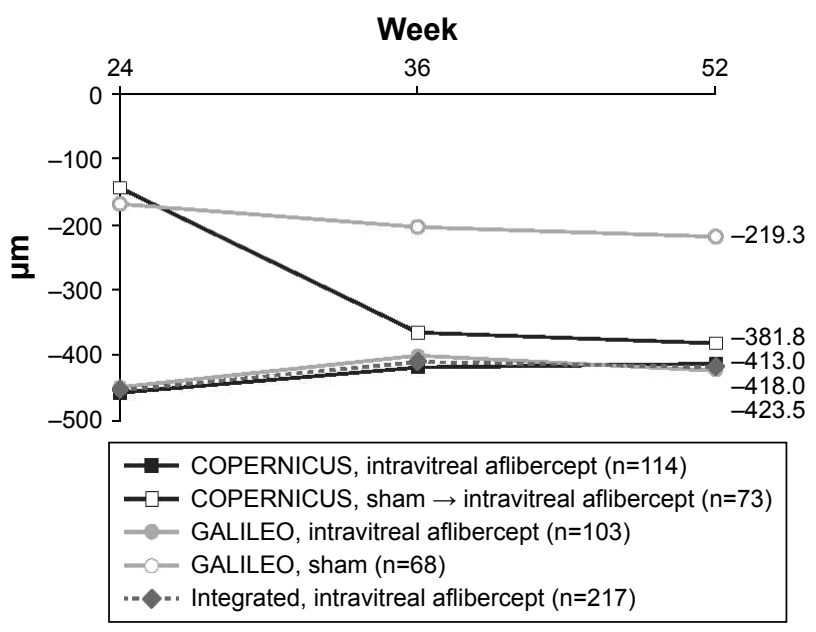

Figure 4 Mean change in CRT from baseline to week 24-week 52 (LOCF). Abbreviations: CRT, central retinal thickness; LOCF, last observation carried forward. may be due to the larger number of patients with non-perfused retinas at baseline in COPERNICUS compared with GALILEO $^{10,13}$ or to some other unidentified factor(s).

The data from the sham $\rightarrow$ intravitreal aflibercept group in COPERNICUS support that a 6-month delay in initiating treatment with intravitreal aflibercept can result in diminished visual and morphologic gains, and after 12 months without treatment, as observed in GALILEO, sham treatment did not show additional visual improvements beyond the small gains seen at week 24 . At week 24, after receiving 6-monthly injections of intravitreal aflibercept, patients in the intravitreal aflibercept group experienced greater visual gains compared with patients who received sham treatment $(+17.7$ letters versus -0.5 letters for the sham group). From week 24 to week 52, visual acuity gains were maintained in the intravitreal aflibercept group. The visual outcomes at week 52 in the sham group of COPERNICUS that crossed over to receive intravitreal aflibercept at week 24 did not reach the level of those attained by patients who received intervention with intravitreal aflibercept at the start of the study, despite a marked improvement in anatomy. Furthermore, patients in the GALILEO study who did not cross over to treatment with intravitreal aflibercept until week 52 also did not show any meaningful visual gains. These data suggest that a delay in treatment initiation with intravitreal aflibercept may result in less optimal visual outcomes.

Integrated morphologic results at week 24 followed the same pattern as the visual results. At week 24, the improvements in CRT from baseline were greater in the intravitreal aflibercept group than in the sham group ( -453.1 versus $-157.2 \mu \mathrm{m}$ ), and these improvements were maintained 
Table 3 Ocular SAEs from baseline to week 52 by MedDRA Preferred Term (safety analysis set)

\begin{tabular}{|c|c|c|c|c|}
\hline & $\begin{array}{l}\text { Intravitreal aflibercept } \\
\text { group }(n=2 \mid 8)\end{array}$ & $\begin{array}{l}\text { Sham } \rightarrow \text { intravitreal } \\
\text { aflibercept group }(n=74)\end{array}$ & $\begin{array}{l}\text { Sham group } \\
(n=68)\end{array}$ & $\begin{array}{l}\text { All patients } \\
(\mathrm{n}=360)\end{array}$ \\
\hline $\begin{array}{l}\text { Patients with } \geq I \text { SAE in } \\
\text { the study eye, } n(\%)\end{array}$ & $16(7.3)$ & $12(16.2)$ & $6(8.8)$ & $34(9.4)$ \\
\hline Cataract & $\mathrm{I}(0.5)$ & $\mathrm{I}(\mathrm{I} .4)$ & 0 & $2(0.6)$ \\
\hline Corneal abrasion & $\mathrm{I}(0.5)$ & 0 & 0 & $\mathrm{I}(0.3)$ \\
\hline Cystoid macular edema & I (0.5) & 0 & 0 & $\mathrm{I}(0.3)$ \\
\hline Endophthalmitis & $\mathrm{I}(0.5)$ & 0 & 0 & I (0.3) \\
\hline Glaucoma & 0 & $3(4.1)$ & $2(2.9)$ & $5(1.4)$ \\
\hline Iris neovascularization & $\mathrm{I}(0.5)$ & $2(2.7)$ & 0 & $3(0.8)$ \\
\hline Macular fibrosis & $\mathrm{I}(0.5)$ & 0 & 0 & $\mathrm{I}(0.3)$ \\
\hline Macular ischemia & $\mathrm{I}(0.5)$ & 0 & 0 & $\mathrm{I}(0.3)$ \\
\hline Macular edema & $4(1.8)$ & 0 & $2(2.9)$ & $6(1.7)$ \\
\hline Retinal artery occlusion & $\mathrm{I}(0.5)$ & 0 & 0 & $\mathrm{I}(0.3)$ \\
\hline Retinal hemorrhage & 0 & $2(2.7)$ & 0 & $2(0.6)$ \\
\hline Retinal tear & 0 & $2(2.7)$ & 0 & $2(0.6)$ \\
\hline Retinal vein occlusion & $2(0.9)$ & I (I.4) & 0 & $3(0.8)$ \\
\hline Visual acuity reduced & $\mathrm{I}(0.5)$ & $\mathrm{I}(\mathrm{I} .4)$ & $\mathrm{I}(\mathrm{I} .5)$ & $3(0.8)$ \\
\hline Vitreous detachment & $\mathrm{I}(0.5)$ & 0 & 0 & I (0.3) \\
\hline Vitreous hemorrhage & $2(0.9)$ & $5(6.8)$ & I (I.5) & $8(7.8)$ \\
\hline
\end{tabular}

Abbreviation: SAE, serious adverse event.

in the intravitreal aflibercept group through week 52 . Although CRT improvements were substantial in the sham $\rightarrow$ intravitreal aflibercept group, anatomic improvements were not mirrored by similar improvements in visual acuity, confirming the importance of early intervention in eyes with macular edema due to CRVO. It should be noted that LOCF data generally leave a gap between patients treated from baseline and patients receiving rescue later on due to dropouts, resulting in an underestimation of the effect of crossover.

The benefits of early treatment have been seen in other studies of patients with CRVO. Analyses of eyes treated with dexamethasone intravitreal implant ${ }^{15}$ and with ranibizumab ${ }^{16}$ in the Phase III trials of these drugs have demonstrated that although the macula can be dried effectively even after a delay in treatment, visual improvements do not catch up to those achieved in earlier-treated eyes.

The results of this integrated analysis of COPERNICUS and GALILEO are consistent with the safety profile of intravitreal aflibercept. The ocular serious adverse events observed in this study largely comprised adverse events attributable to the underlying disease.

\section{Conclusion}

Based on the integrated data from the COPERNICUS and GALILEO studies, intravitreal aflibercept is a well-tolerated and effective treatment for macular edema secondary to CRVO. The integrated data show that macular edema secondary to CRVO can be managed successfully with initial monthly intravitreal aflibercept injections, consistent with results shown in the respective trials. ${ }^{10,12}$ Delay in treatment initiation with intravitreal aflibercept in the COPERNICUS study resulted in limited gains in visual acuity by week 52 . The integrated results of these studies reinforce the robustness of the treatment effect of intravitreal aflibercept in retinal vein occlusions to maximize visual and morphologic benefits.

Table 4 APTC-ATEs from baseline to week 52 (safety analysis set)

\begin{tabular}{lllll}
\hline & $\begin{array}{l}\text { Intravitreal aflibercept } \\
\text { group }(\mathbf{n}=\mathbf{2 1 8})\end{array}$ & $\begin{array}{l}\text { Sham } \rightarrow \text { intravitreal } \\
\text { aflibercept group }(\mathbf{n}=\mathbf{7 4})\end{array}$ & $\begin{array}{l}\text { Sham group } \\
(\mathbf{n}=\mathbf{6 8})\end{array}$ & $\begin{array}{l}\text { All patients } \\
(\mathbf{n}=\mathbf{3 6 0})\end{array}$ \\
\hline Patients with any APTC-ATE, $\mathrm{n}(\%)$ & $\mathrm{I}(0.5)$ & $\mathrm{I}(\mathrm{I}) \mathrm{4})$ & 0 & $2(0.6)$ \\
$\quad$ Non-fatal myocardial infarction & $\mathrm{I}(0.5)$ & 0 & 0 & $\mathrm{I}(0.3)$ \\
Non-fatal stroke & 0 & 0 & 0 & 0 \\
Vascular death & 0 & $\mathrm{I}(\mathrm{I.4)}$ & 0 & $\mathrm{I}(0.3)$ \\
\hline
\end{tabular}

Abbreviation: APTC-ATEs, Antiplatelet Trialists Collaboration-defined arterial thromboembolic events. 


\section{Acknowledgments}

The authors wish to thank the COPERNICUS and GALILEO study investigators. Medical writing assistance was provided by Corey Eagan, MPH, of PAREXEL and was funded by Bayer. COPERNICUS and GALILEO were sponsored by Bayer and Regeneron Pharmaceuticals, Inc.

\section{Disclosure}

Amelie Pielen has received research funding from Novartis, Bayer, Roche, Genentech, and Théa Pharm and has been a lecturer and consultant for Novartis, Allergan, and Bayer Pharmaceuticals. W Lloyd Clark is a consultant for Genentech, Ohr Pharmaceuticals, Regeneron Pharmaceuticals, Inc., Roche, and Santen; offers research support for Allergan, Genentech, Regeneron Pharmaceuticals, Inc., Roche, and Santen; and has equity in VERSYL, Inc. David S Boyer is a consultant for Aerpio, Alcon, Alimera, Allegro, Allergan, Bausch \& Lomb, Bayer, CoDa Therapeutics, Foresight Biotherapeutics, Genentech, GenSight Biologics, GrayBug Vision, GlaxoSmithKline, Neurotech, Notal Vision, Novartis, Ophthotech, Ohr, Optos, Regeneron Pharmaceuticals, RetroSense, Regulus Therapeutics, Sun Pharmaceuticals, StemCells, and ThromboGenics; is a lecturer for Alcon and Allergan; and holds minor equity in Allegro, Neutotech, Ohr, and Ophthotech. Yuichiro Ogura is a consultant to Alcon, Janssen Pharma, and Wakamoto and has received financial support from Bausch \& Lomb, Bayer, Kissei Pharma, Kowa, Novartis, Santen, Sanwa Kagaku, Senju, and Topcon. Frank G Holz is a consultant to Acucela, Genentech/Roche, Novartis, Bayer, Alcon, OPTOS, Heidelberg Engineering, Carl Zeiss Meditec, Allergan, and Pfizer and has received financial support from OPTOS, Heidelberg Engineering, Carl Zeiss Meditec, Alcon, Genentech/Roche, Bayer, and Novartis. Jean-Francois Korobelnik is a consultant to Alcon, Alimera, Allergan, Bayer, Horus, Novartis, Roche, Thea, and Zeiss. Brigitte Stemper, Friedrich Asmus, Kay D Rittenhouse, and Christiane Ahlers are employees of Bayer. Robert Vitti and Namrata Saroj are employees of Regeneron Pharmaceuticals, Inc. Oliver Zeitz is a former employee of and consultant to Bayer. Julia A Haller is a consultant to KalVista, Merck, Janssen, Novartis, and Thrombogenics and a board member of Celgene. The authors report no other conflicts of interest in this work.

\section{References}

1. Ho M, Liu DT, Lam DS, Jonas JB. Retinal vein occlusions, from basics to the latest treatment. Retina. 2016;36(3):432-448.

2. Wong TY, Scott IU. Clinical practice. Retinal-vein occlusion. $N$ Engl J Med. 2010;363(22):2135-2144.

3. Klein R, Klein BE, Moss SE, Meuer SM. The epidemiology of retinal vein occlusion: the Beaver Dam Eye Study. Trans Am Ophthalmol Soc. 2000;98:133-141.

4. Klein R, Moss SE, Meuer SM, Klein BE. The 15-year cumulative incidence of retinal vein occlusion: the Beaver Dam Eye Study. Arch Ophthalmol. 2008;126(4):513-518.

5. Rogers S, McIntosh RL, Cheung N, et al; International Eye Disease Consortium. The prevalence of retinal vein occlusion: pooled data from population studies from the United States, Europe, Asia, and Australia. Ophthalmology. 2010;117(2):313-319.

6. Pielen A, Feltgen N, Isserstedt C, Callizo J, Junker B, Schmucker C. Efficacy and safety of intravitreal therapy in macular edema due to branch and central retinal vein occlusion: a systematic review. PLoS One. 2013;8(10):e78538.

7. Deissler HL, Lang GK, Lang GE. Capacity of aflibercept to counteract VEGF-stimulated abnormal behavior of retinal microvascular endothelial cells. Exp Eye Res. 2014;122:20-31.

8. Papadopoulos N, Martin J, Ruan Q, et al. Binding and neutralization of vascular endothelial growth factor (VEGF) and related ligands by VEGF Trap, ranibizumab and bevacizumab. Angiogenesis. 2012; 15(2):171-185.

9. Boyer D, Heier J, Brown DM, et al. Vascular endothelial growth factor Trap-Eye for macular edema secondary to central retinal vein occlusion six-month results of the phase 3 COPERNICUS study. Ophthalmology. 2012;119(5):1024-1032.

10. Brown DM, Heier JS, Clark WL, et al. Intravitreal aflibercept injection for macular edema secondary to central retinal vein occlusion: 1-year results from the phase 3 COPERNICUS study. Am J Ophthalmol. 2013; 155(3):429-437.

11. Heier JS, Clark WL, Boyer DS, et al. Intravitreal aflibercept injection for macular edema due to central retinal vein occlusion: two-year results from the COPERNICUS study. Ophthalmology. 2014;121(7): 1414-1420.

12. Holz FG, Roider J, Ogura Y, et al. VEGF Trap-Eye for macular oedema secondary to central retinal vein occlusion: 6-month results of the phase III GALILEO study. Br J Ophthalmol. 2013;97(3):278-284.

13. Korobelnik JF, Holz FG, Roider J, et al. Intravitreal aflibercept injection for macular edema resulting from central retinal vein occlusion: one-year results of the phase 3 GALILEO study. Ophthalmology. 2014; 121(1):202-208.

14. Ogura Y, Roider J, Korobelnik JF, et al; GALILEO Study Group. Intravitreal aflibercept for macular edema secondary to central retinal vein occlusion: 18-month results of the phase 3 GALILEO study. Am J Ophthalmol. 2014;158(5):1032-1038.

15. Yeh WS, Haller JA, Lanzetta P, et al. Effect of the duration of macular edema on clinical outcomes in retinal vein occlusion treated with dexamethasone intravitreal implant. Ophthalmology. 2012;119(6): 1190-1198.

16. Campochiaro PA, Brown DM, Awh CC, et al. Sustained benefits from ranibizumab for macular edema following central retinal vein occlusion: twelve-month outcomes of a phase III study. Ophthalmology. 2011; 118(10):2041-2049. 


\section{Supplementary material}

List of Institutional Review Boards and Ethic Committees for COPERNICUS and GALILEO sites COPERNICUS

USA: Copernicus Group IRB, UCSD Human Research Protection Program, Cleveland Clinic IRB, IRB, OPRS; Canada: The University of British Columbia Office of Research Services Clinical Research Ethics Board, IRB Services, Capital District Health Authority Research Ethics Board, University of Western Ontario Health Sciences Research Ethics Board, Research Ethics Research and Development Vancouver Island Health Authority, Sunnybrook Research Ethics Board; India: Regional Institute of Ophthalmology; Ethics Committee Hyderabad Eye Research Foundation, Narayana Nethralaya Institutional Ethics Committee; Israel: Helsinki Committee of Tel Aviv, Helsinki Committee of Rabin Medical Center, Helsinki Committee of Kaplan Medical Center, Helsinki Committee of Meir Medical Center; Colombia: Instituto Nacional de Investigacion en Oftalmologia - INIO, Comite de etica en Investigacion de Fundacion Oftalmological Nacional - FUNDONAL.

\section{GALILEO}

Australia: Bellberry Human Research Ethics Committee, Royal Prince Alfred Hospital, The Royal Victorian Eye \& Ear Hospital; Austria: Ethikkommission der Medizinischen Universität Wien und des AKH, Ethikkommission des Landes Oberösterreich, Ethikkommission des KH Barmherzige Brüder Linz; France: Comite de Protection des Personnes sud ouest et Outremer III; Germany: Ethikkommission an der Medizinischen Fakultät Rheinische Friedrich-Wilhelms-Universität Bonn, Bereich Humanmed. d. Georg-August-Universität Göttingen Medizinische Fakultät Ethik-Kommission, Ethik-Kommission bei der Ärztekammer des Saarlandes, Ethik-Kommission bei der Ärztekammer Hamburg, Ethik-Kommission bei der Landesärztekammer Hessen, Ethikkommission der Ärztekammer Westfalen-Lippe, EthikKommission der Landesärztekammer Rheinland-Pfalz, EthikKommission der Sächssischen Landesärztekammer, Klinikum der Christian-Albrechts-Universität Ethik-Kommission,

Clinical Ophthalmology

\section{Publish your work in this journal}

Clinical Ophthalmology is an international, peer-reviewed journal covering all subspecialties within ophthalmology. Key topics include: Optometry; Visual science; Pharmacology and drug therapy in eye diseases; Basic Sciences; Primary and Secondary eye care; Patient Safety and Quality of Care Improvements. This journal is indexed on

Submit your manuscript here: http://www.dovepress.com/clinical-ophthalmology-journal
Ethik-Kommision der Medizinischen Fakultät der EberhardKarls-Universität und am Universitätsklinikum Tübingen, Ethikkommission des Fachbereichs Humanmedizin, Klinikum rechts der Isar Fakultät für Medizin Ethik-Kommission, Ethikkommission an der Medizinischen Fakultät Rheinische Friedrich-Wilhelms-Universität Bonn, Ethik-Kommission der Technischen Universität Dresden, Ethik-Kommission der Medizinischen Fakultät der Universität zu Köln, Ethik-Kommission der Medizinischen Fakultät der Universität Leipzig, Universitätsklinik Gießen und Marburg $\mathrm{GmbH}$ Standort Marburg Ethik Kommission, Universitätsklinikum Aachen Ethik-Kommission an der Medizinischen Fakultät, Ethik-Kommission der Medizinischen Fakultät der Universität Duisburg-Essen, Universitätsklinikum Freiburg Ethik-Kommission, Ethikkommission der Med. Fakultät Heidelberg, Universitätsklinikum Regensburg Ethikkommission der medizinischen Fakultät, Universitätsklinikum Schleswig-Holstein/AÖR Ethikkommission; Hungary: ETT Klinikai Farmakológiai Etikai Bizottság, ETT Klinikai Farmakológiai Etikai Bizottság; Italy: Comitato etico per la sperimentazione clinica dei medicinali dell' A.O.U. Careggi, Comitato Etico A.O.U. Ospedali Riuniti Umberto I-LancisiSalesi, Comitato Etico A.O.U. Policlinico Consorziale di Bari, Comitato Bioetico dell'Azienda Ospedaliero-Universitaria Policlinico di Catania, Comitato Etico Indipendente Presso la Fondazione PTV Policlinico Tor Vergata, Comitato Etico della ASL RM/A di Roma, Comitato Etico ASL TO/2 di Torino, Comitato Etico IRCCS Fondazione S.Raffaele del Monte Tabor di Milano, Comitato di Etica Fondazione Irccs Ca'Granda Ospedale Maggiore Policlinico; Japan: Juntendo University Urayasu Hospital IRB, Kyoto University Hospital IRB, Nagoya City University Hospital IRB, Nagoya University Hospital IRB, Osaka University Hospital IRB, Surugadai Nihon University Hospital IRB; South Korea: Asan Medical Center, Gachon University Gil Medical Center, Seoul National University Bundang Hospital IRB, Seoul National University Hospital IRB, Severance Hospital Institutional Review Board, St Mary Hospital IRB; Latvia: Ethics Committee for Clinical Trials; Singapore: NHG Domain Specific Review Boards (DSRB), Singhealth Centralised Institutional Review Board.

\section{Dovepress}

PubMed Central and CAS, and is the official journal of The Society of Clinical Ophthalmology (SCO). The manuscript management system is completely online and includes a very quick and fair peer-review system, which is all easy to use. Visit http://www.dovepress.com/ testimonials.php to read real quotes from published authors. 